\title{
Investigation of the relationship between fitness and physical activity level with serum levels of nerve growth factor and markers of blood- brain permeability in people with multiple sclerosis: the role of body composition
}

\author{
Mostafa Khodadoost $^{1}$, Raoof Negaresh ${ }^{2}$, Motahare Mokhtarzade ${ }^{2}$, Rouholah Rabjbar $^{3}$ \\ ${ }^{1}$ Department of Physical Education, Abadan branch, Islamic Azad University, Abadan, Iran \\ ${ }^{2}$ Department of Physical Education and Sport Sciences, Faculty of Humanities, Tarbiat Modares University, Tehran, \\ Iran \\ ${ }^{3}$ Department of Sports Physiology, Shahid Chamran University of Ahvaz, Ahvaz, Iran
}

\begin{abstract}
Background: Nerve growth factors reduction and blood-brain barrier distribution is one of the characteristics of multiple sclerosis (MS). Active life-style is known as a complementary and important strategy in MS therapy. The aim of the current study was to investigate the relationship between aerobic capacity and physical activity with serum level of nerve growth factors and markers of blood-brain barrier permeability in MS patients with normal weight or overweight.

Materials and methods: In this study, 61 patients with MS (31 normal weight and 30 overweight) participated. Aerobic capacity and physical activity level were evaluated by the progressive cycling test and Baecke questionnaire. The levels of nerve growth factors and blood-brain barrier markers were measured by ELISA kit. Pearson and regression test were used to examine the relationship between variables.

Results: A significant correlation was found between the level of physical activity and aerobic capacity with brain-derived neurotrophic factor (BDNF) and S100 calcium-binding protein B (S100B) in all participants, while BDNF concentrations were only associated with the aerobic capacity in the normal weight group. There was a significant relationship between $\mathrm{s} 100 \mathrm{~b}$ and both variables in the overweight group. Regression results showed that aerobic capacity independently predicted $20 \%$ and $30 \%$ of changes in BDNF and s100b.

Conclusion: In general, physical activity and fitness levels have a significant correlation with BDNF and s100b in people with MS, which can be modulated by the body composition. Therefore, physical activity can consider as complementary therapies in people with multiple sclerosis.
\end{abstract}

Keywords: Multiple sclerosis, Blood-brain barrier, Nerve growth factors, Overweight.

Cited as: Khodadoost M, Negaresh R, Mokhtarzade M, Rabjbar R. Investigation of the relationship between fitness and physical activity level with serum levels of nerve growth factor and markers of blood-brain permeability in people with multiple sclerosis: the role of body composition. Medical Science Journal of Islamic Azad University, Tehran Medical Branch 2019; 29(3): 222-231.

Correspondence to: Mostafa Khodadoost

Tel: +989164262029

E-mail: khodadust.m@gmail.com

ORCID ID: 0000-0001-7899-0831

Received: 17 Sep 2018; Accepted: 6 Jan 2019 
مجله علوم يزشكى دانشعاه آزاد اسلامى

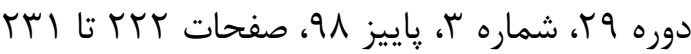

Original

Article

\section{بررسى ارتباط آمادكى جسمانى و سطح فعاليت بدنى با سطوح سرمى عوامل رشد عصبى و ماركرهاى نفوذيذيرى سد خونى مغزى در افراد مبتلا به مالتييل اسكلروزيس: نقش تركيب بدن}

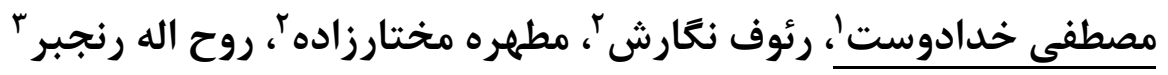

' كروه تربيت بدنى، واحد آبادان، دانشكاه آزاد اسلامى، آبادان، ايران

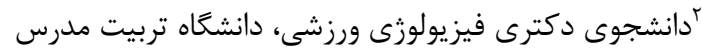

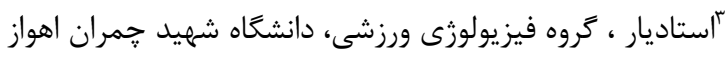

جكبده سابقه و هدف: از ويثكى هاى بيمارى مالتيبل اسكلروزيس(MS)، كاهش غلظت عوامل رشد عصبى و اختلال در سد خونى-مغنى است.

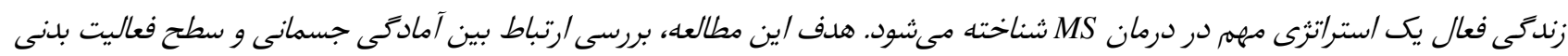

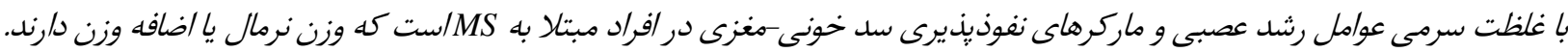

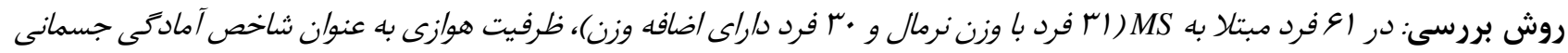

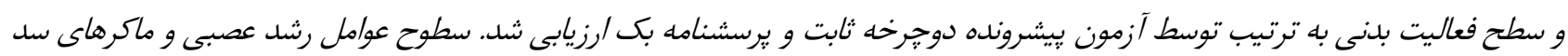

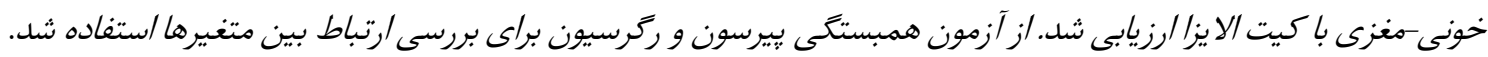

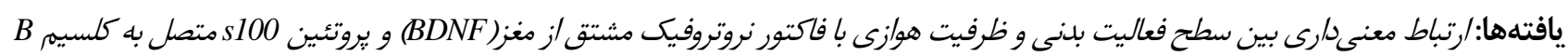

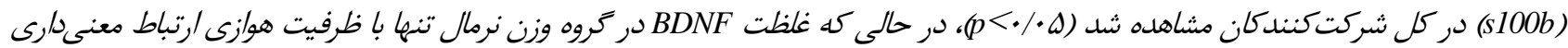

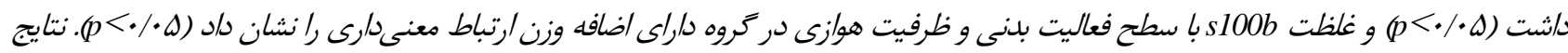

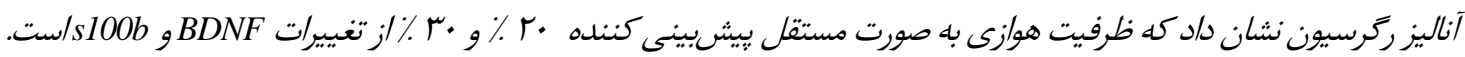

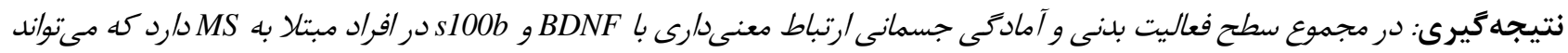
به وسيله وضعيت تركيب بلن افراد تعديل شود.

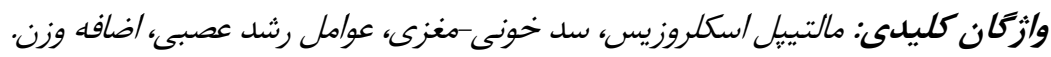

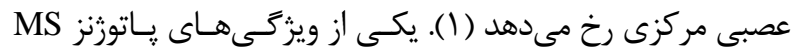
مقلهم

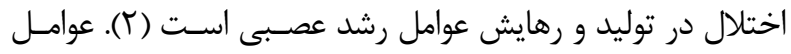

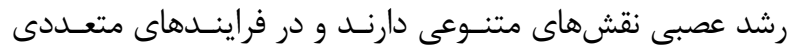

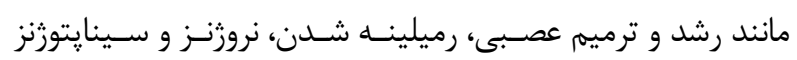

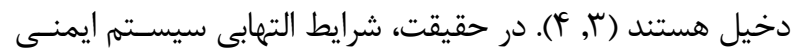

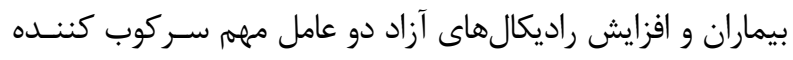

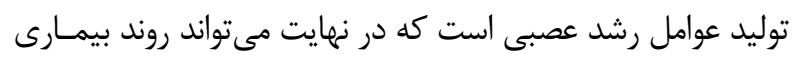
مالتييل اسكلروزيس(MS) يك بيمـارى خـود ايمنسى و دميلينـهـ كننده سيستم عصبى مركزى است كه به علت هجوم سـلولهـاى

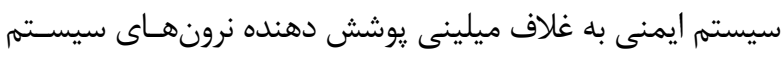


عوامل رشد عصبى و ماكرهاى سد خونى مغزى به عنـوان فرضـيه اصلى بررسى شد.

\section{مواد و روشهها}

مطالعـه حاضـر توسـط كميتـهـ اخـلاق در يـرزوهش دانشـعًاه آزاد اسلامى آبادان تاييد شد. براساس معيارهاى ورود و خــروج، از بــين رl ا فرد مبتلا به MS نوع عود-بهبود (RRMS) كه اطلاعات آنهـا از انجمن MS خوزستان اخذ شد، طبـق شـكل ا، 99 نفـر (سـن بالاتر از \1 سال) به عنوان نمونه نهايى در نظر گرفتـه شـد. تمـام منافع و خطرات يزوهش براى شركت كنند

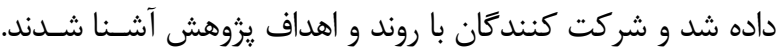
سيس رضايت نامه آكاهانه توسط شركت كنندگان تكميل شد.

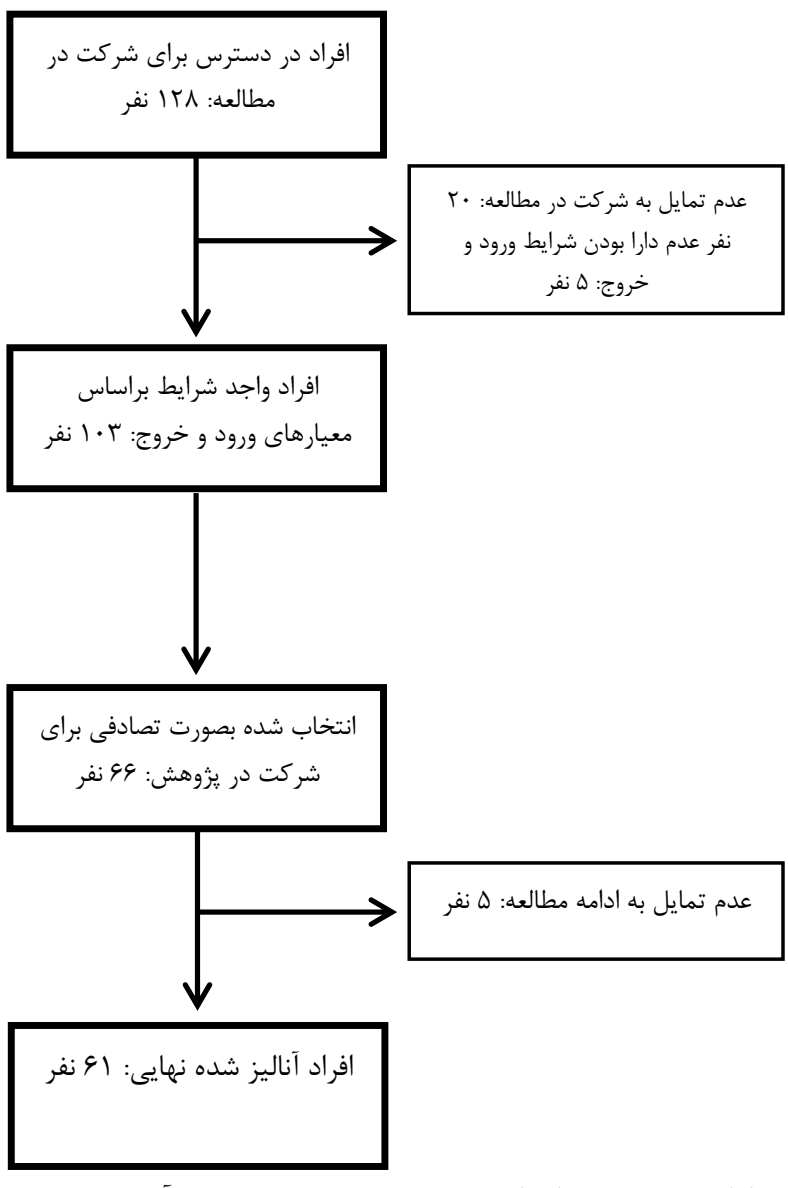

شكل ا. دياكرام جكَونكَى انتخاب شركت كنندَان و آناليز نهايى

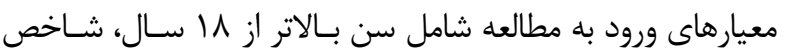

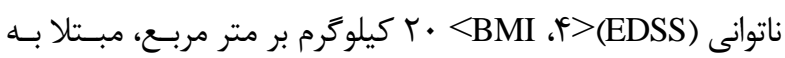

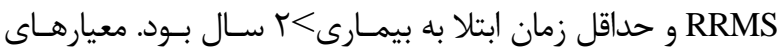
خروج از مطالعـه شـامل تغييـر داروهـاى مصـرفى در شـش مـاه

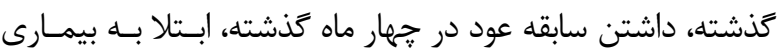

همانطور كه افزايش التهـاب و توليـد راديكـال هـاى آزاد سـركوب كننده توليد و رهايش عوامل رشد عصبى است، مىتواند منجر بــه

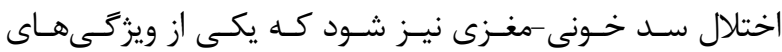

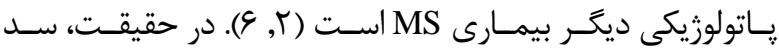
خونى -مغزى، فيلتر بسيار دقيقى بــين خَردش خــون محيطى و

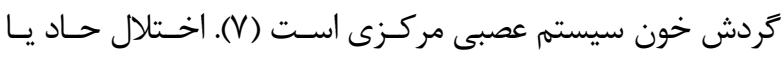

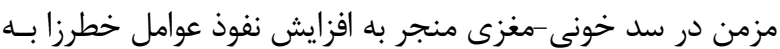
داخل سيسستم عصبى مركزى مىشود كه تشديد كننده شـرايط

التهابى و دميلينه شدن عصبى خواهد شد (^).

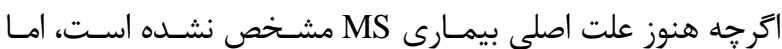
محققان عقيده دارند تركيبى از عوامل ارثى و محيطى مسى توانــد در يـاتوزنز ايسـن بيمـارى دخيـل باشـند ( (1, 9). بــراى مثــال در

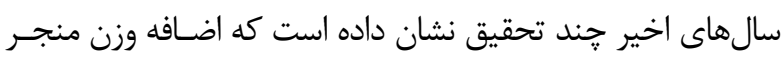
به افزايش ريسك ابتلا به MS مـىشـود (• (, 11). در مطالعـهاى

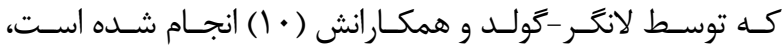

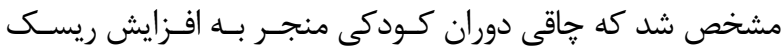
ابتلا به MS مى شود. از طرفى ديخر، هدرستوم و همكارانش (11) با بررسى اله | فV فرد مبتلا به MS دريافتند كه افرادى كه در سـن

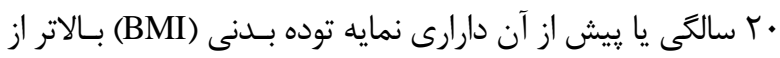

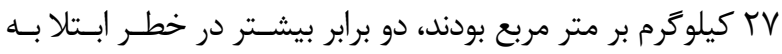
f. بودند. جالب توجه است كه در ميان بيمـاران MS

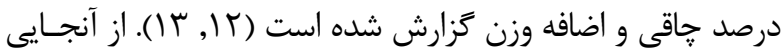

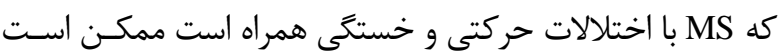
از طريق كـاهش فعاليـت بـدنى منجــر بــهـ افـزايش وزن و تغييـر تركيب بدن شود. اين در حالى است كه برخلاف عقيده اوليـهـ كـهـ بيماران MS را از فعاليت بدنى بر حذر مىداشت، مطالعات كنـونى

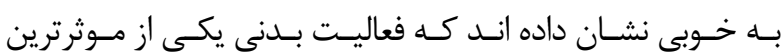
استراترىهاى درمانى مكمل در افراد مبتلا به MS است (9, \& ( ). تاكنون مطالعهاى وجود نداشته است كه به بررسى ارتبـاط سـطح دمانى

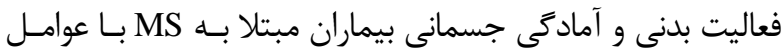

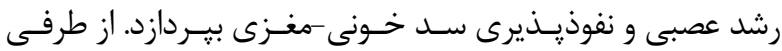
مشخص شده است كه تركيب بدن مىتوانـد يـك تعـديل كنـــده

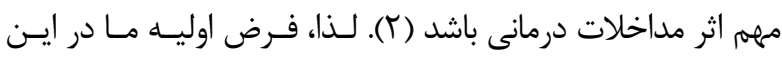

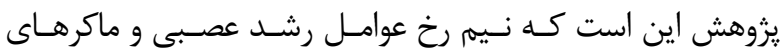
نفوذيذيرى سد خونى -مغزى در افراد مبتلا به MS با وزن نرمـال و داراى اضافه وزن متفاوت است. همجٍنين، ما به دنبـال ايسن بـوديم

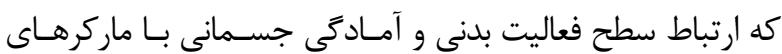
مذكور را بررسى كنيم. در نهايت، نقش تركيب بدنى به عنوان يك

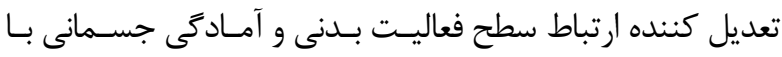


خونى-مغزى نيز است (ז, 9). در مطالعه حاضـر، سـطح سـرمى

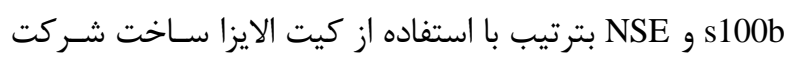
ضAbnova ضريب تغيير(CV) تمـام كيـت هـاى اسـتفاده شـده كمتــر از 1 و درص بود.

براى ارزيابى سطح فعاليت بدنى از يرسشنامه اسـتاندارد و بــين

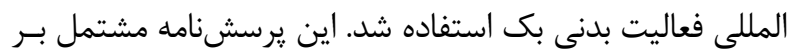
19 سوال (براساس مقياس ليكرت) است كه سطح فعاليت بـدنى

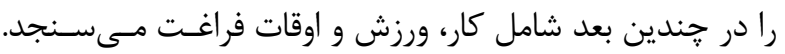

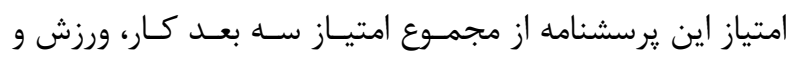

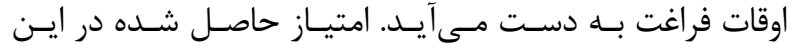

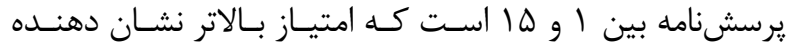

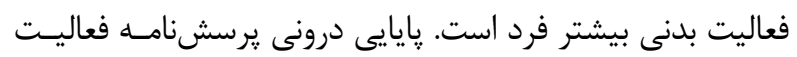

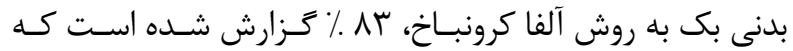

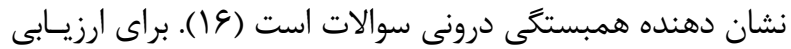

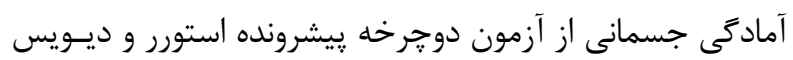

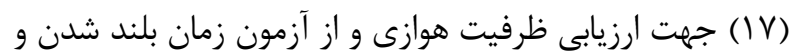
رفتن (TUG) استفاده شد. در آزمون دوجرخه يِ ريشـرونده، ابتـدا

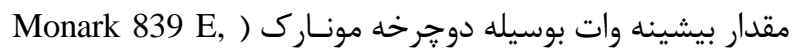
(Dalarna, Sweden

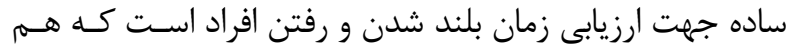

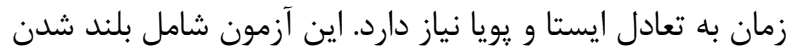

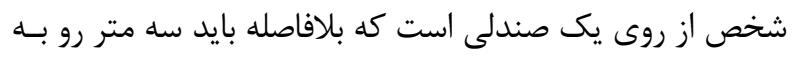
جلو حركت كند، دور مـانع دور بزنســــ و سـه متــ بركـردد (1) (1).

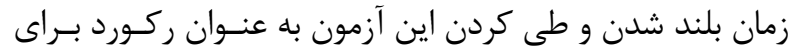
هر شخص توسط كرونومتر ثبت شد.

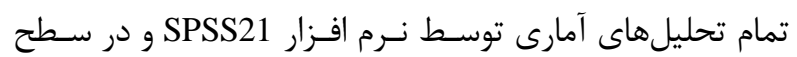

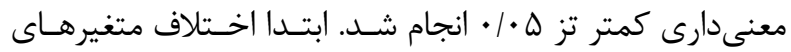

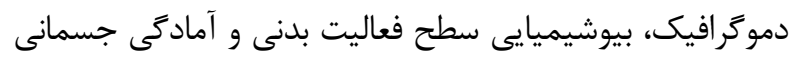

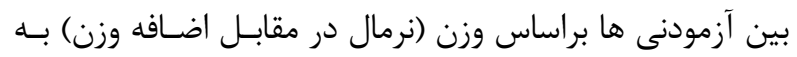

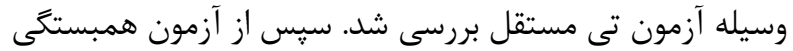

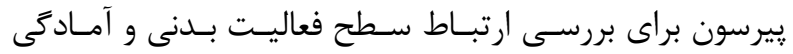

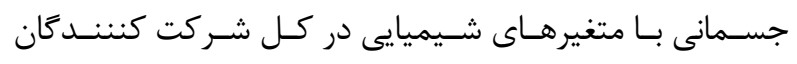

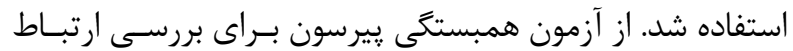

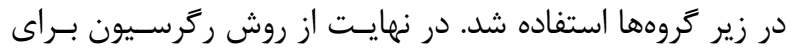

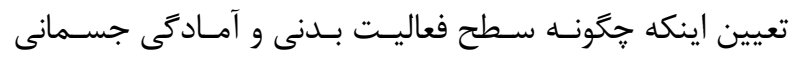
مستقلا مىتوانند سطح متغييرهاى بيوشـيميايى را بــيش بينى كنند استفاده شد.
هاى مزمن جانبى مانند ديابت، سيكار كشيدن و اسـتفاده از رزيـهم

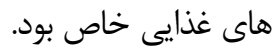

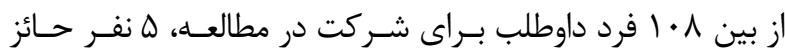

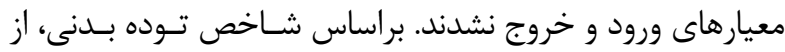

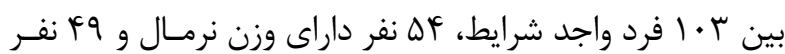

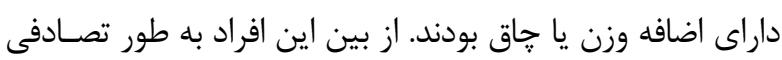

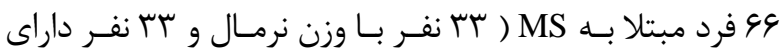

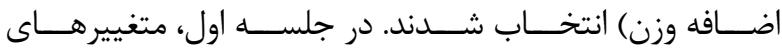

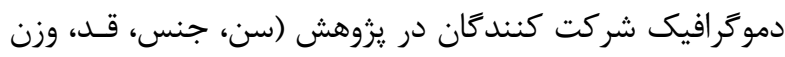

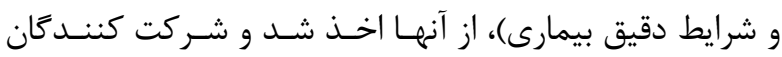

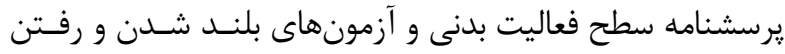

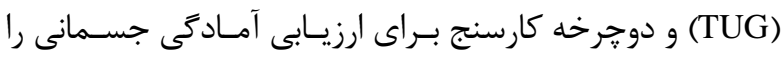

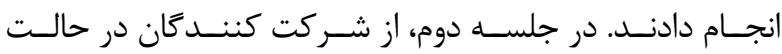

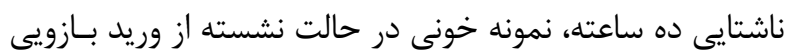
جهت ارزيابى متغيرهاى بيوشيمايى اخذ شد.

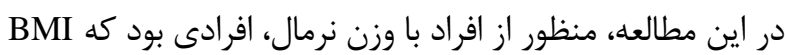

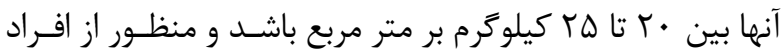

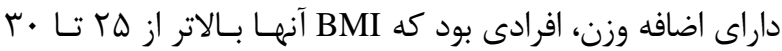

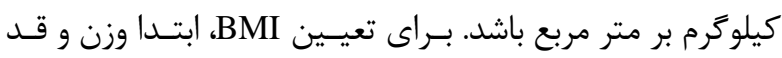

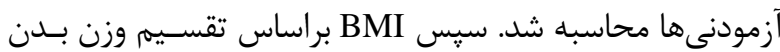
(برحسب كيلوگَرم) بر مجذور قد(برحسب متر) محاسبه شد.

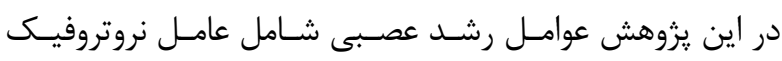

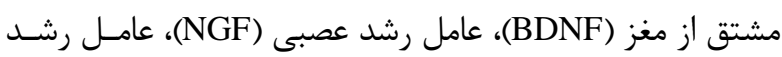

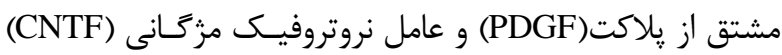
بود. سطح سرمى عوامل رشد عصبى به روش الايزا محاسبه شد.

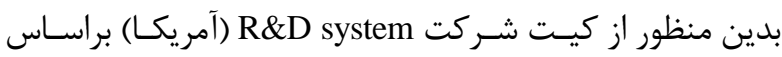
راهنماى شركت سازنده براى ارزيـابى BDNF و NGF اسـتفاده شد. همجنين سطح سرمى PDGF و الايزا ساخت شركت IBL International GMBH (آلمان) اندازه

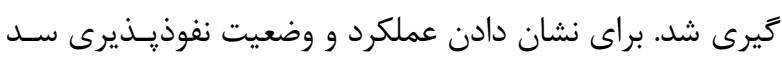

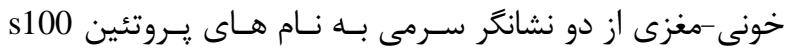
متصل به كلسيم (s100b)B و انولاز ويزه نـرون(NSE) اسـتفاده

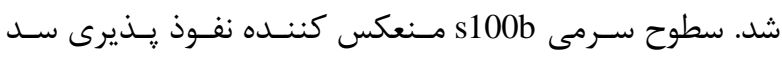

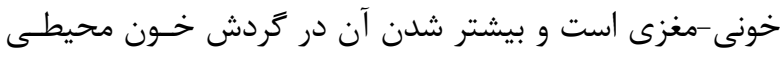

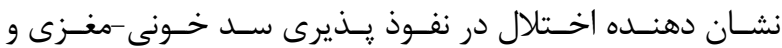

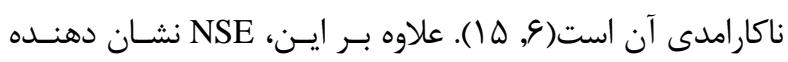

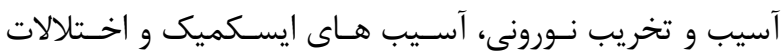
ساختارى در ديواره سلول هاى عصبى است (؟). با وجود اينكـه،

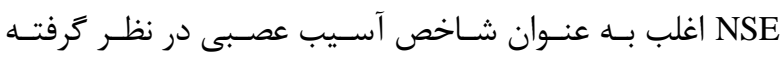

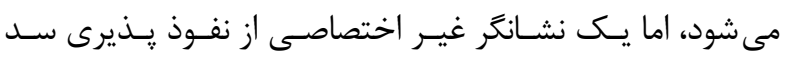


معكوسى وجود دارد، اما ارتباط مثبت و معنىدارى با غلظت

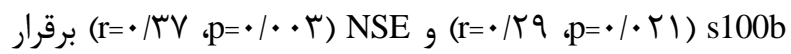
است. ارتباط معنى دارى بين ديخر عوامل ارزيابى شده مشاهده

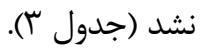

جدول r. ارتباط سطح فعاليت بدنى و آمادگى جسمانى (ظرفيت

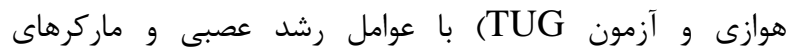

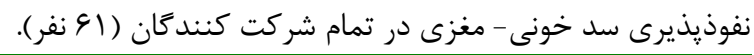
NSE S100b CNTF PDGF NGF BDNF

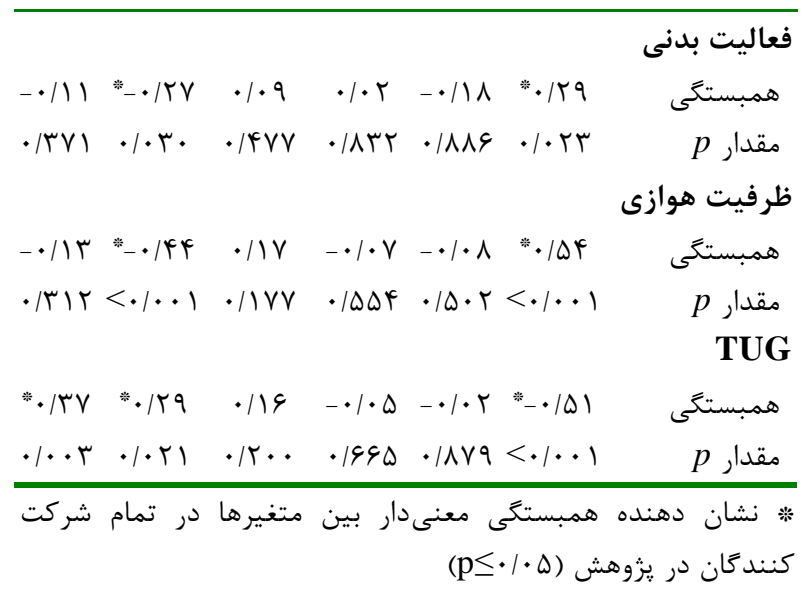

سيس آزمون همبستگى بيرسون بين متغيرهايى كه همبستخى

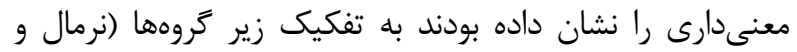

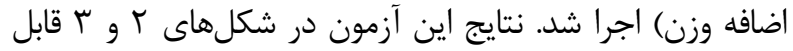

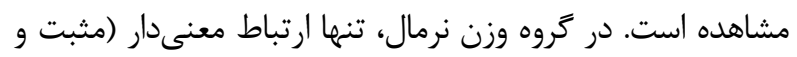

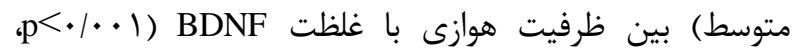

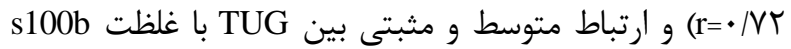

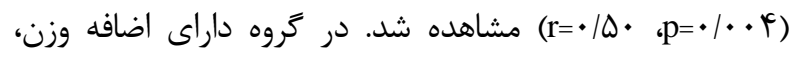

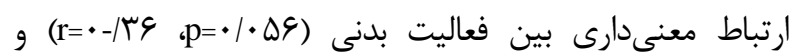

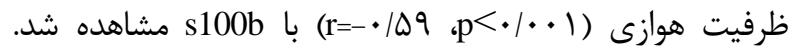

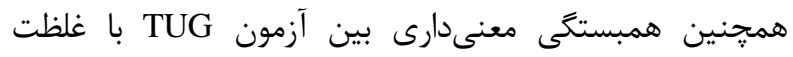
$(\mathrm{r}=\cdot / \omega \cdot \mathrm{p}=\cdot / \cdot \bullet)$ NSE, $(\mathrm{r}=-\cdot / \Delta 9, \mathrm{p}<\cdot / \cdot \cdot 1)$ BDNF

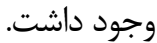
ما از آزمون ركرسيون به شيوه ورود مرحلهاى براى تعيين اينكه

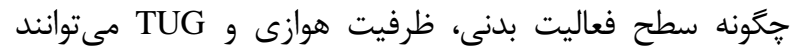
ييش بينى كننده غلظت BDNF، s100b و NSE باشند، استفاده

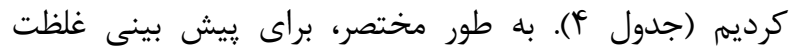

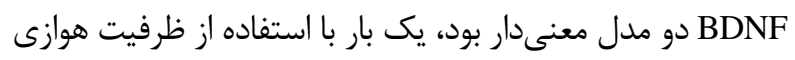

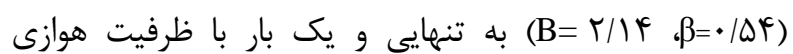

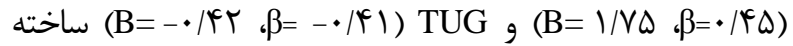

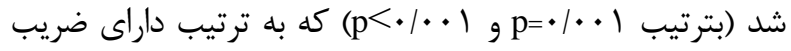

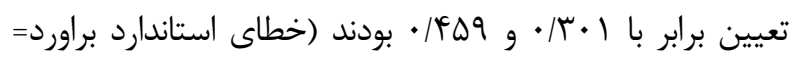

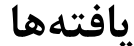

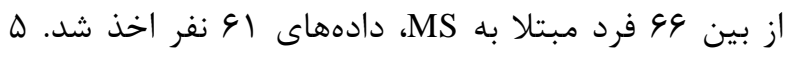

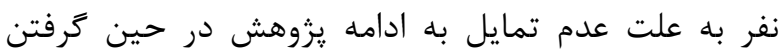

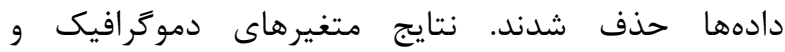
بيوشيميايى در جدولهاى ا و r مشاهده مىشوند. جدول ا. جدول توصيفى متغيرهاى دموكرافيك و فعاليت بدنى در

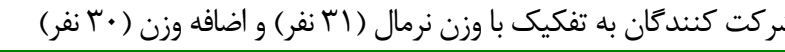

\begin{tabular}{|c|c|c|}
\hline كروه اضافه وزن & كروه نرمال & متغيير \\
\hline$\Gamma r / / T \pm T / 9 \varphi$ & $r \cdot / r \cdot \pm r / / r$ & سن (سال ) \\
\hline$V V / \widetilde{\sim} \perp \pm F / \Lambda F$ & $" q \cdot / r \cdot \pm r / r q$ & $(\mathrm{~kg})$. \\
\hline
\end{tabular}

$r V / 9 \Delta \pm 1 / T r \quad " r / / \Delta V \pm 1 / / 9 \quad\left(\mathrm{~kg} / \mathrm{m}^{2}\right) B M I$

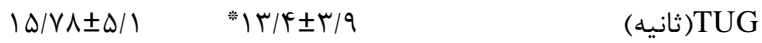

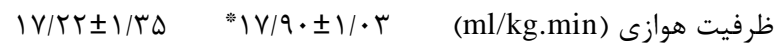
فعاليت بدنى $1 / \Lambda \pm 1 / 1 \quad 1 / \Delta \pm 1 \quad$ EDSS

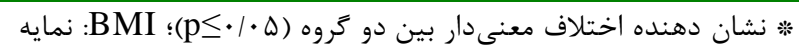

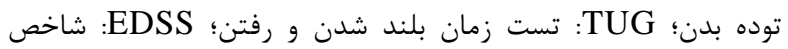

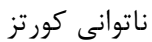

جدول r. جدول توصيفى عوامل رشد عصبى و ماركرهاى

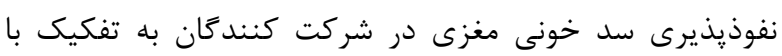

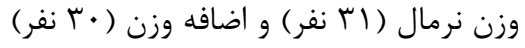

\begin{tabular}{|c|c|c|}
\hline كروه اضافه وزن & كروه نرمال & متغيير \\
\hline$r \mid / \Delta V \pm F / \Lambda 1$ & $" T \Delta / \varphi \wedge \pm \varphi$ & $(\mathrm{mg} / \mathrm{ml}) \mathrm{BDNF}$ \\
\hline$r q 9 / \Delta) \pm \lambda \psi / q 9$ & $r q 4 / \cdot 1 \pm 1 \cdot F / 10$ & $(\mathrm{pg} / \mathrm{ml}) \mathrm{NGF}$ \\
\hline$\Delta \mid \Delta / \cdot q \pm \psi V V / r V$ & $F q V / A T \pm F T / A F$ & $(\mathrm{pg} / \mathrm{ml})$ PDGF \\
\hline $99 / r \pm N / \cdot r$ & $991.9 \pm 1 / 94$ & (pg/ml)CNTF \\
\hline$\Delta Q / T Y \pm 1 \cdot / \cdot \Lambda$ & $\Delta 1 / T V \pm 1 \cdot / 9 \Delta$ & $(\mathrm{mg} / \mathrm{l}) \mathrm{S} 100 \mathrm{~b}$ \\
\hline$V(\Lambda) \pm 1 / \cdot r$ & $" 9 / 9 \mathrm{~V} \pm . / 9 \mathrm{~T}$ & $(\mathrm{ug} / \mathrm{l}) \mathrm{NSE}$ \\
\hline
\end{tabular}

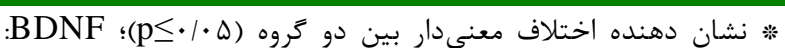

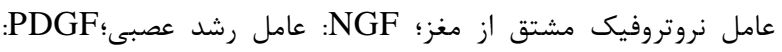

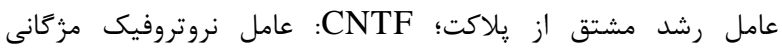

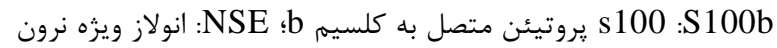

نتايج حاصل از آزمون همبستگى يبرسون بين نشانكرهاى آمادكى

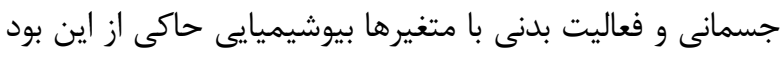

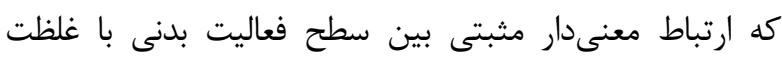
BDNF

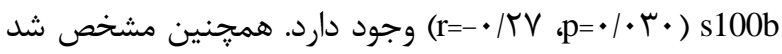

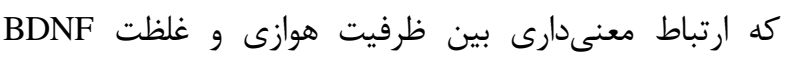

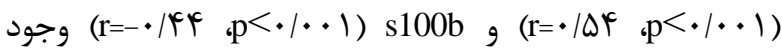
دارد. در نهايت مشاهده شده كه بين نتايج حاصل از آزمون TUG

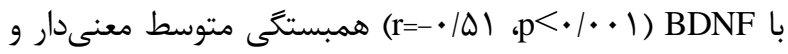


جدول F. نتايج آناليز ركرسيون و مدل هاى ساخته شده براى بيش

\begin{tabular}{|c|c|c|c|c|c|}
\hline & & & & & بينى متغي \\
\hline ضريب & مقدار & خطاى & B & مدل & متغير \\
\hline همبستكى & $p$ & معيار & & & \\
\hline$\cdot \pi \cdot 1$ & .1 .94 & $V / \uparrow \wedge \Delta$ & $-\mid \psi / \cdot \cdot r$ & مقدار & BDNF \\
\hline & $\cdot 1 \cdot .1$ & - ATS & T/MFE & ثابت & \\
\hline & & & & ظرفيت & \\
\hline & & & & هوازى & \\
\hline$\cdot / 4 \Delta q$ & - /A95 & $V / T \Delta V$ & $-1 / \cdot \cdot 0$ & مقدار & ${ }^{\#} \mathrm{BDNF}$ \\
\hline & $.1 \cdot .1$ & $\cdot / 4 \wedge 9$ & $1 / V \Delta V$ & ثابت & \\
\hline & $\cdot \mid \cdot \cdot 1$ & . $11 \cdot r$ &.$- / F T \Delta$ & ظرفيت & \\
\hline & & & & هوازى & \\
\hline & & & & TUG & \\
\hline$\cdot / r \cdot$ & .1 .10 & IV/TYY & $119 / 994$ & مقدار & S100b \\
\hline & $\cdot / . .1$ &.$/ 9 \wedge F$ & - r/VAI & ثابت & \\
\hline & & & & ظرفيت & \\
\hline & & & & هوازى & \\
\hline.$/ 1 \mu \wedge$ & $\cdot 1 \cdot .1$ & $\cdot|f \Delta|$ & $\Delta / 91 /$ & مقدار & NSE \\
\hline & r. &.$/ r q$ & .1 .9$. & ثابت & \\
\hline & & & & TUG & \\
\hline
\end{tabular}

"براى ييش بينى غلظت BDNF دو مدل معنى دار وجود داشت.

بحث

مطالعه حاضر، اولين مطالعهاى است كه همبستگى بين سطح فعاليت بدنى و آمادىى جسمانى (ظرفيت هوازى وTUG ) افراد

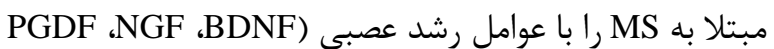
و (CNTF) و ماركرهاى عملكرد سد خونى-مغزى (s100b و (NSE را با تمركز به شرايط وزنى بررسى مى كند. هدف از از

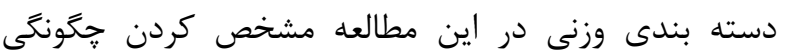

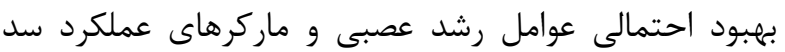
خونى-مغزى در קاسخ به فعاليت بدنى است، زير إِيش إز إز اين

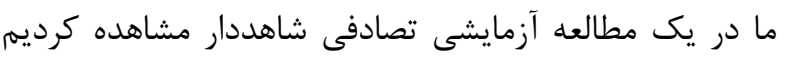
كه يتانسيل קاسخ عوامل رشد عصبى به يك دوره تمرين هوازى متناوب وابسته به وزن افراد است، به طورى كه غلنه

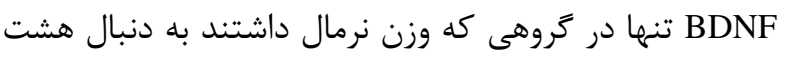
هفته تمرين بهبود معنى دارى داشت (T).

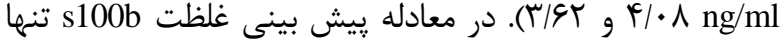

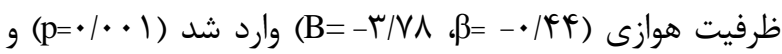

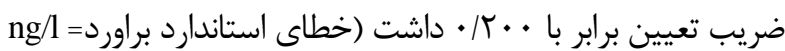
9/4). براى ييش بينى غلظت NSE نيز با توجه به نتايج آزمون

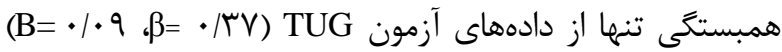

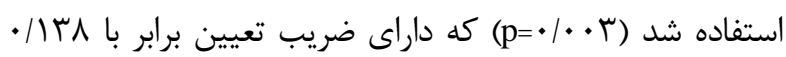

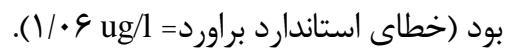
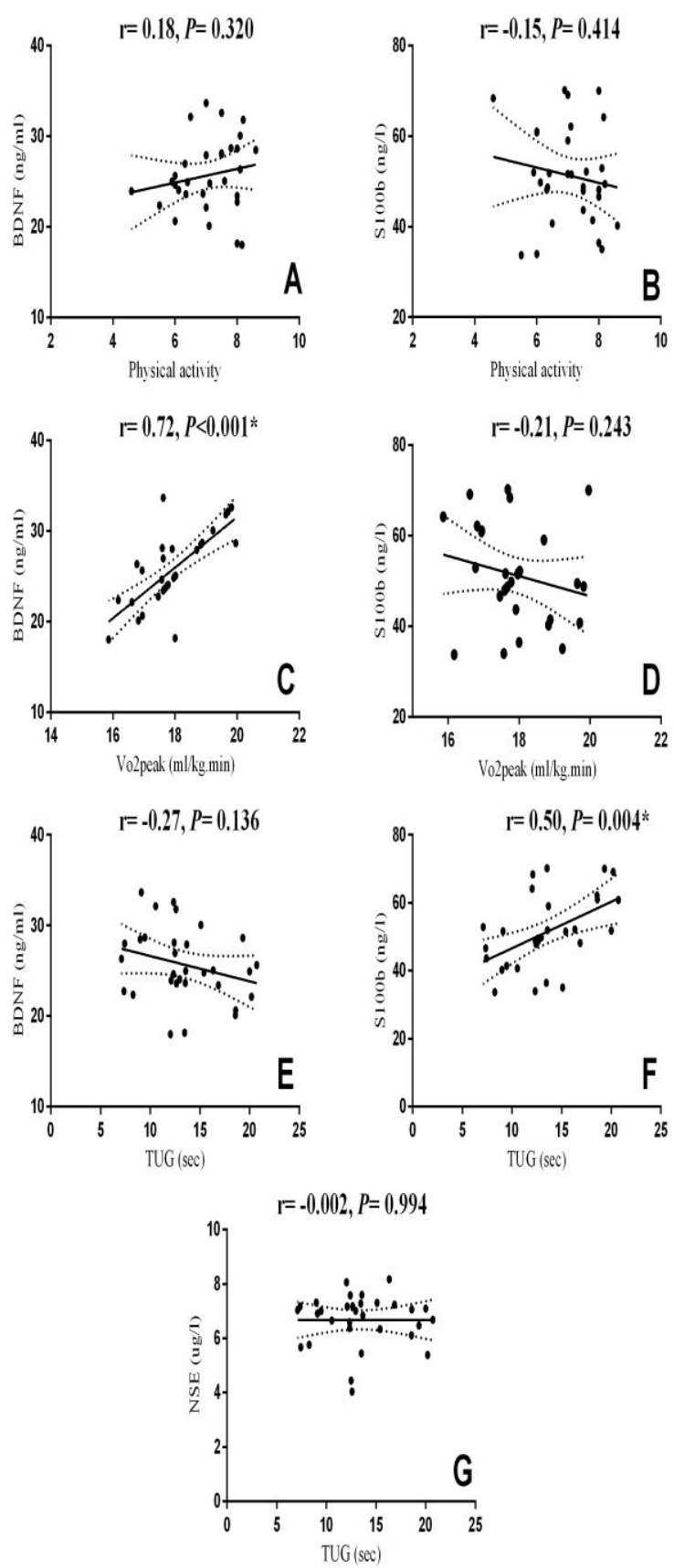

شكل r. بررسى همبستگى سطح فعاليت بدنى و آمادكى جسمانى

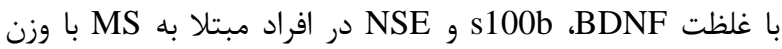
نرمال. * نشان دهنده همبستخى معنى دار (ه •|• 
داشته است (9) (1). اين در حالى بود كه ميزان توليد

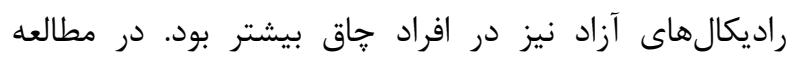

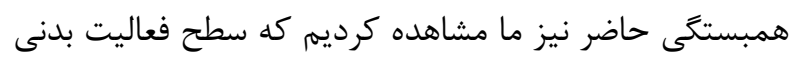

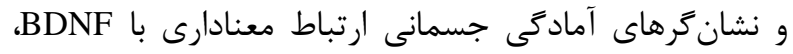

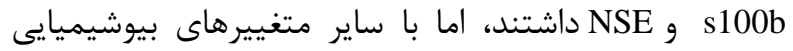

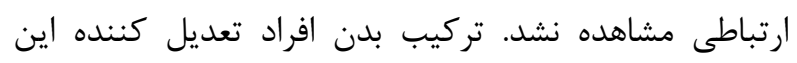

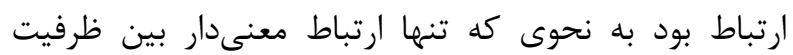

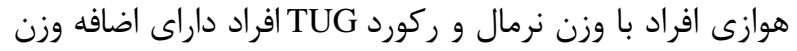

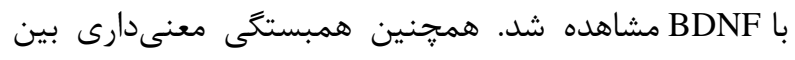

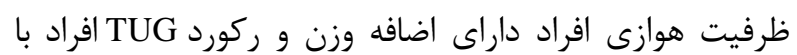
وزن نرمال با s100b وجود داشت. در نهايتا غلظت NSE تنها

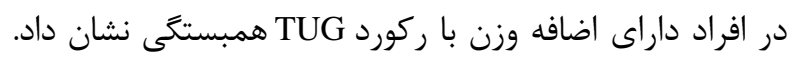

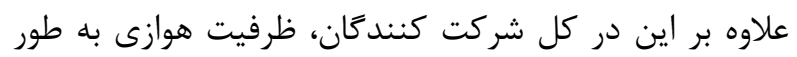

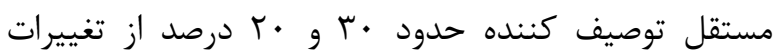

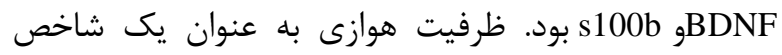

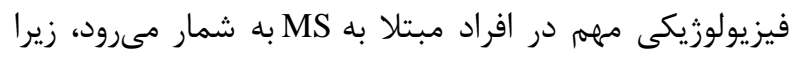

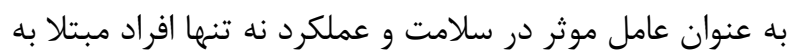
MS بلكه افراد سالم نيز شناخته مىشود (·怆). به علاوه، ظرفيت هوازى ارتباط تنكاتنكى با خطر ابتلا به ساير بيمارىها مانند بيمارىهاى قلبى و عروقى و حتى تخريب ساختارهاى

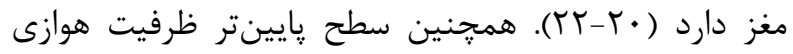

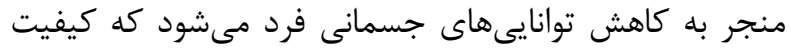

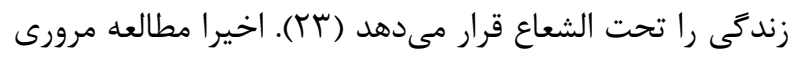

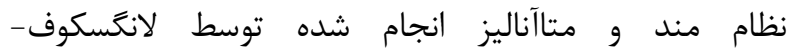

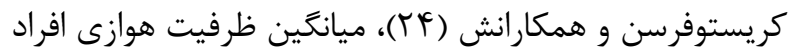

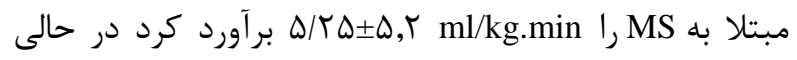
كه اين مقدار براى افراد سالم طور مشابه ما نيز مشاهده كرديم كه ظرفيت هوازى بيماران مبتلا به MS به خصوص در افرادى كه داراى اضافه وزن بودند،

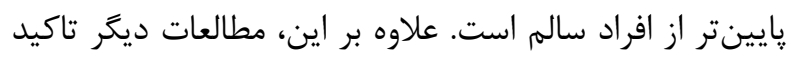

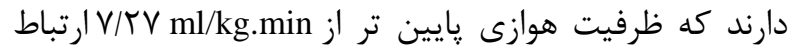

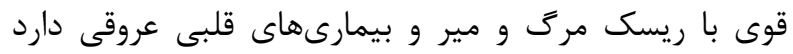

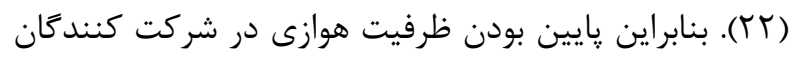

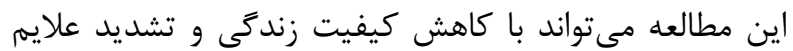
بيمارى همراه باشد. ميزان ظرفيت هوازى در بيماران با باضافه وزن پايينتر بود كه اين مىتواند به علت بالاتر بودن احتمالى بردي

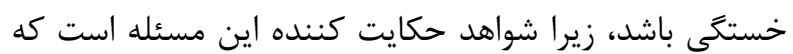

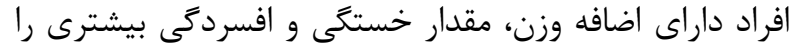

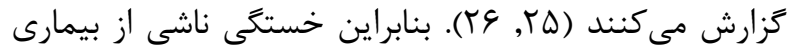
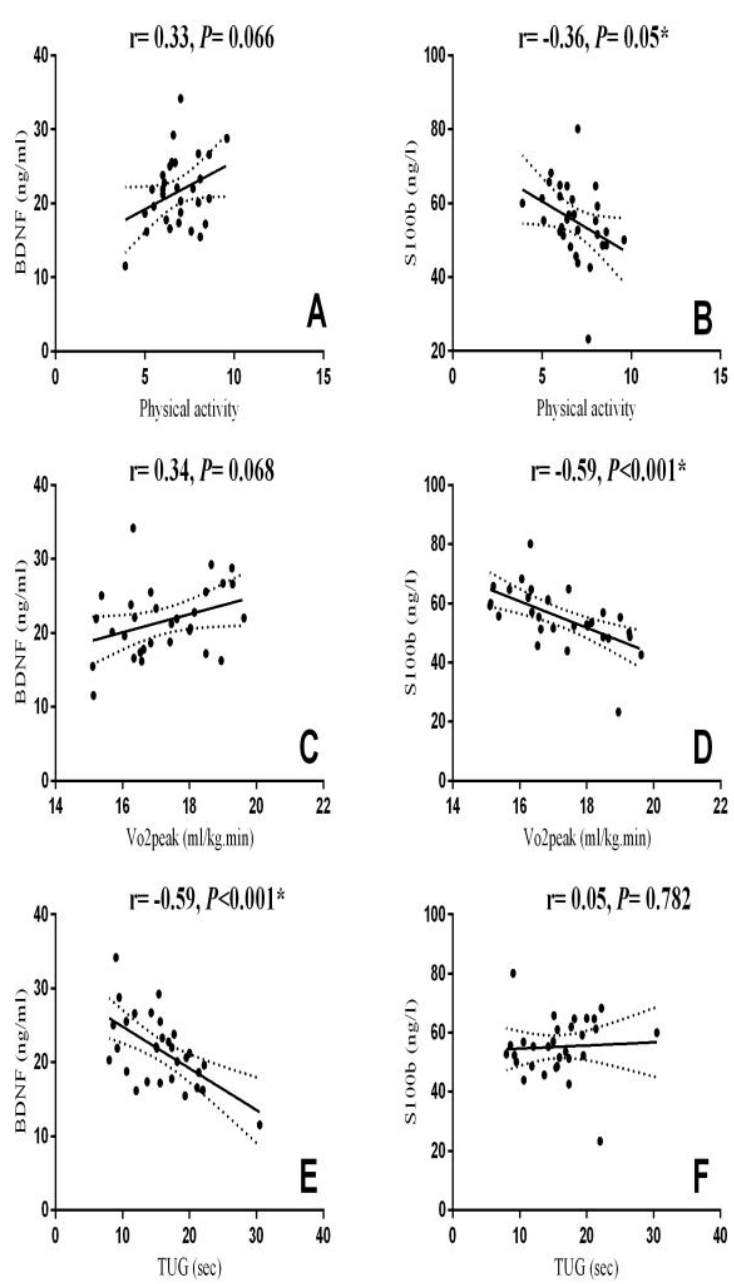

$r=0.50, P=0.005^{*}$

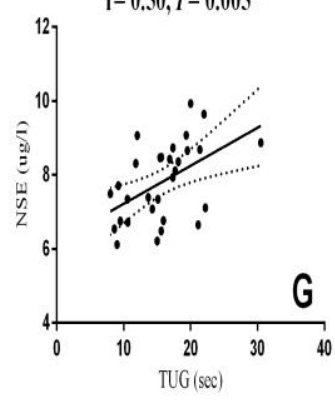

شكل rّ. بررسى همبستگى سطح فعاليت بدنى و آمادكى جسمانى

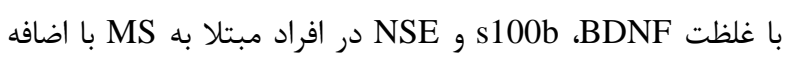

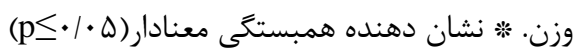

با اين حال، تفاوت معنىدارى بين پِاسخ سايتوكاينها، خستكى و افسردگى افراد مبتلا به MS داراى وزن نرمال و والين اضافه وزن مشاهده نشد (Y). همجنين مطالعه ديكرى كه اثر

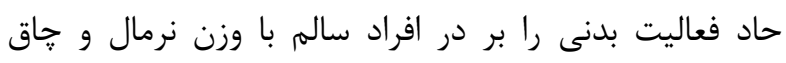

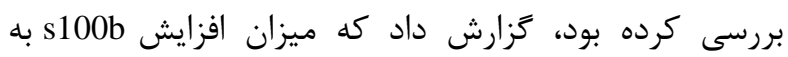

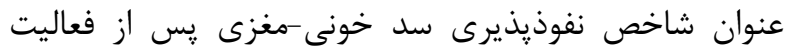

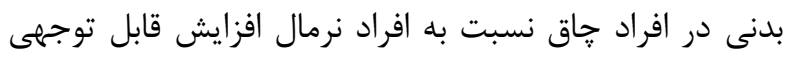


در يك دهه اخير توجه ويزماى به مسئله اضافه وزن در بيمارى شده است و آن را به عنوان يك ريسك فاكتور و يك إن

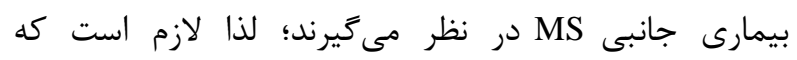

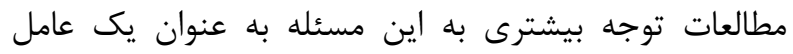

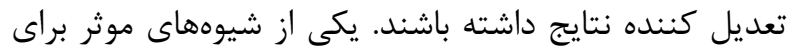

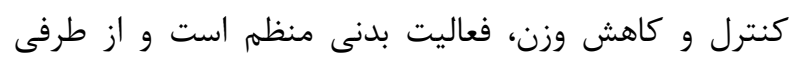

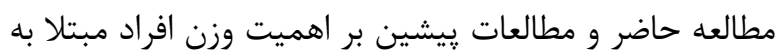
MS در سازحارى به مداخلات بزوهشى (مانند فعاليت بدنى

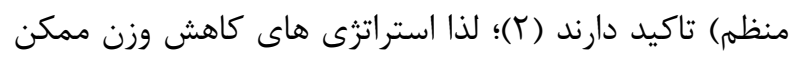

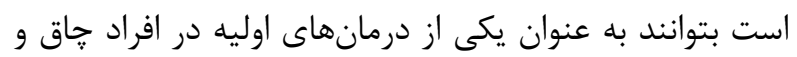

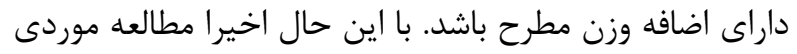

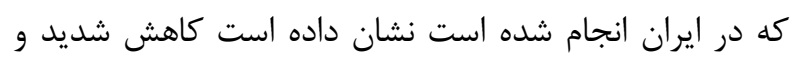

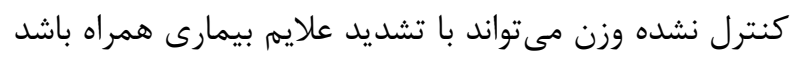

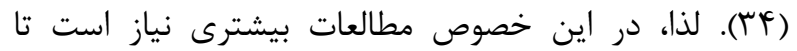

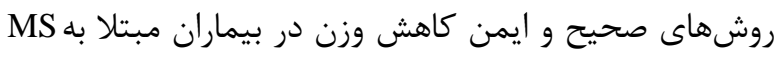

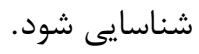
مطالعه حاضر קندين محدوديت دارد. ابتدا اندازه نمونه كوجى به خصوص در زير كروهها از محدوديتهاى اين يزوهش است كه مىتواند بر نتايج حاصل از آزمون ركرسيون

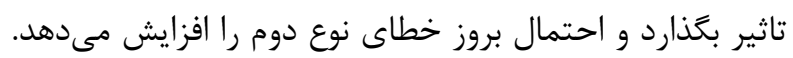

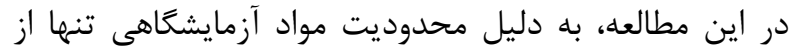

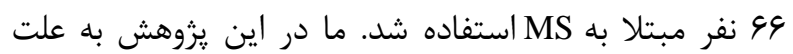

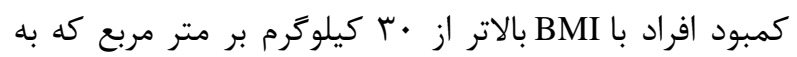

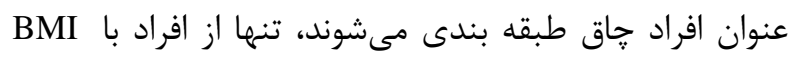

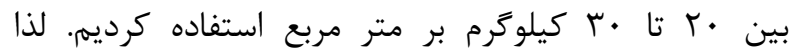

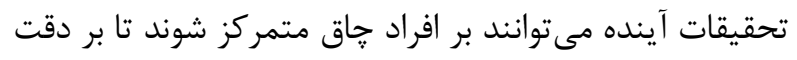

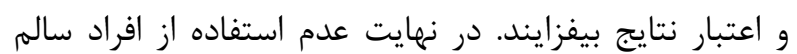
متناظر با شركت كنندكان حاضر در يزوهش محدوديت نئن

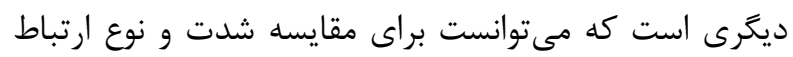
بين متغيرها مفيد باشد. در مجموع نتايج اين مطالعه نشان مىدهد كه سطح فعاليت باليد

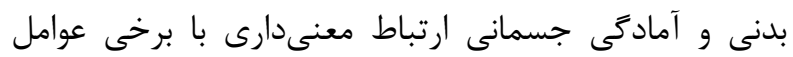

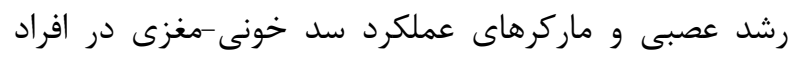
مبتلا به MS دارد كه مىتواند به وسيله وضعيت تركيب بدن

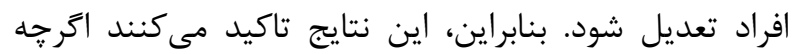

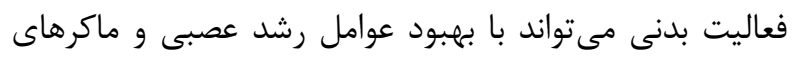
سد خونى -مغزى همراه باشد، اما تركيب بدن يكى فئن فاكتور مهمه و تعيين كننده در جكَونكى اين ياسخ به فعاليت بدنى است.
مى تواند به عنوان يكى از مانعهاى مهمم فعاليت بدنى باشد

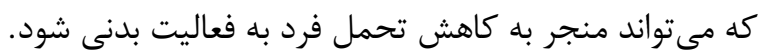

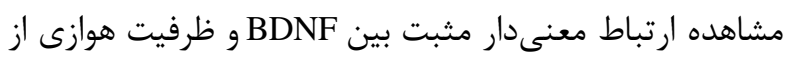

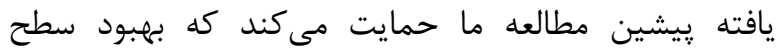

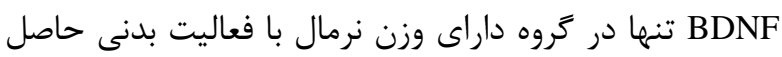

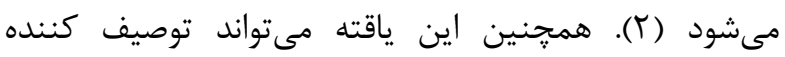

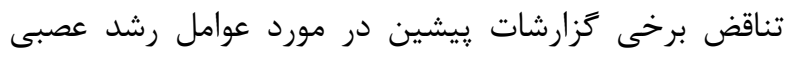

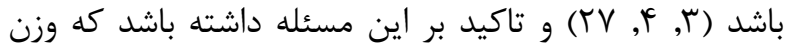

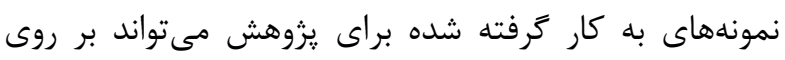

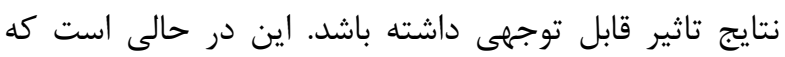

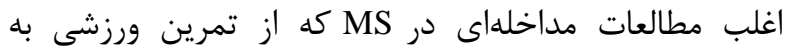

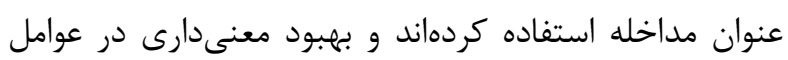

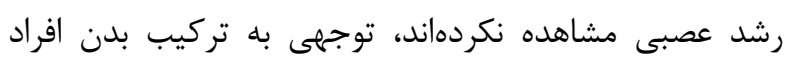

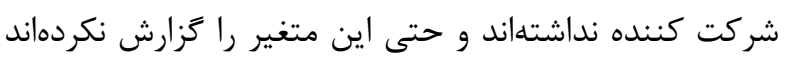

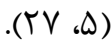

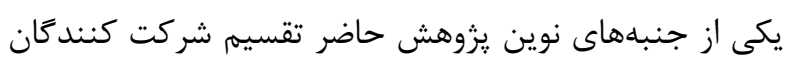

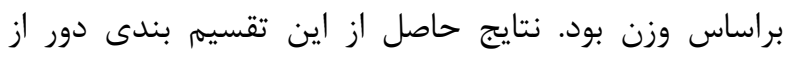

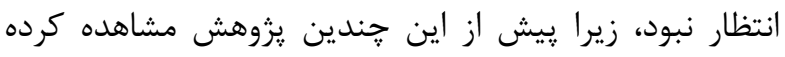

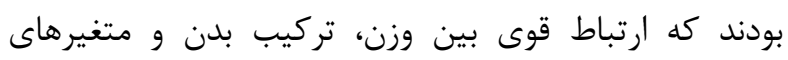

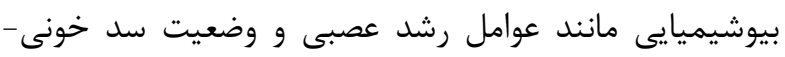

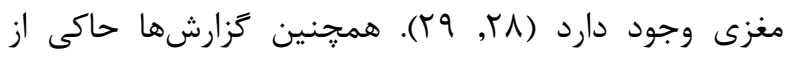

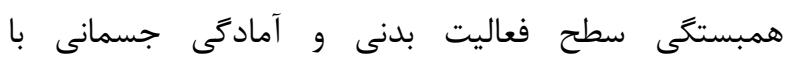

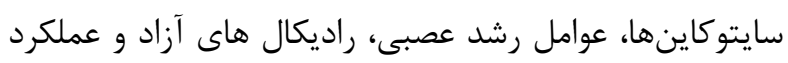

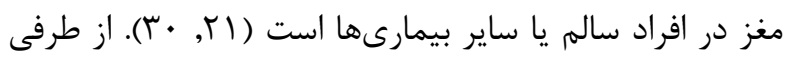
مطالعه بِيشين ما نيز نشان داده بود كه ظرفيت هوازى ارتباط

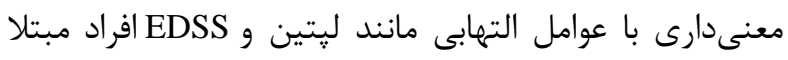

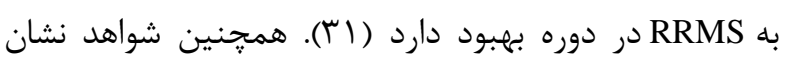

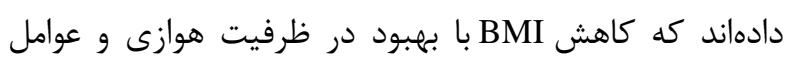

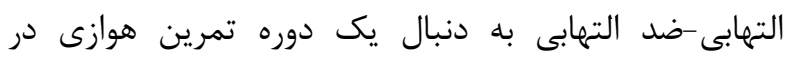

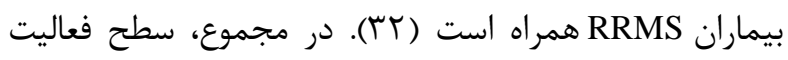

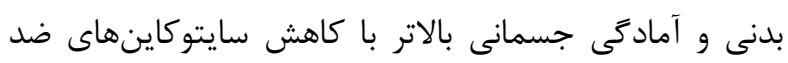

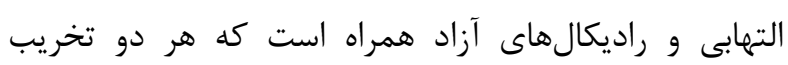

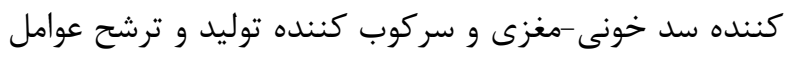

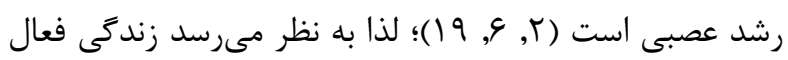

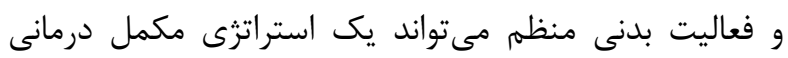

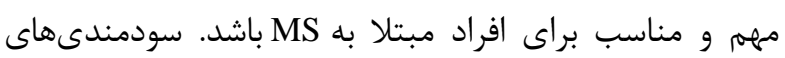

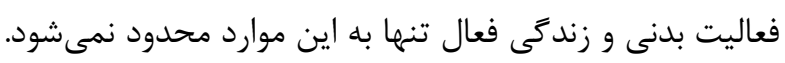

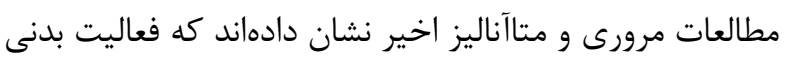

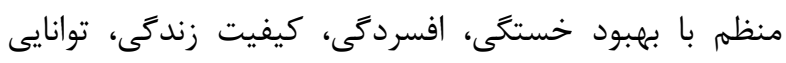

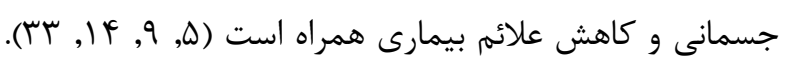




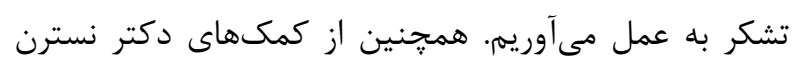
مجدى نسب و دكتر روبرت موتل تشكر مى كنيم.
با توجه به اينكه اين مطالعه حاصل طرح تحقيقاتى مصوب

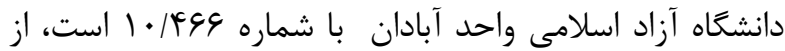

\section{REFERENCES}

1. McDonald WI, Compston A, Edan G, Goodkin D, Hartung HP, Lublin FD, et al. Recommended diagnostic criteria for multiple sclerosis: guidelines from the International Panel on the diagnosis of multiple sclerosis. Ann Neurol 2001;50:121-7.

2. Mokhtarzade M, Motl R, Negaresh R, Zimmer P, Khodadoost M, Baker JS, et al. Exercise-induced changes in neurotrophic factors and markers of blood-brain barrier permeability are moderated by weight status in multiple sclerosis. Neuropeptides 2018;70:93-100.

3. Bansi J, Bloch W, Gamper U, Kesselring J. Training in MS: influence of two different endurance training protocols (aquatic versus overland) on cytokine and neurotrophin concentrations during three week randomized controlled trial. Mult Scler 2013;19:613-21.

4. Ozkul C, Guclu-Gunduz A, Irkec C, Fidan I, Aydin Y, Ozkan T, et al. Effect of combined exercise training on serum brain-derived neurotrophic factor, suppressors of cytokine signaling 1 and 3 in patients with multiple sclerosis. $\mathrm{J}$ Neuroimmunol 2018;316:121-9.

5. Mokhtarzade. The role of physical activity on modulation of nerve growth factors [Brain-Derived Neurotrophic Factor (BDNF) and Nerve Growth Factor (NGF)] in patients with multiple sclerosis: A systematic review. Journal of Isfahan Medical School 2017;1:1-12.

6. Roh H-T, Cho S-Y, Yoon H-G, So W-Y. Effect of Exercise Intensity on Neurotrophic Factors and Blood-Brain Barrier Permeability Induced by Oxidative-Nitrosative Stress in Male College Students. Int J Sport Nutr Exerc Metab 2017;27:139-46.

7. Obermeier B, Daneman R, Ransohoff RM. Development, maintenance and disruption of the blood-brain barrier. Nat Med 2013;19:1584-96.

8. Ortiz GG, Pacheco-Moisés FP, Macías-Islas MÁ, Flores-Alvarado LJ, Mireles-Ramírez MA, González-Renovato ED, et al. Role of the blood-brain barrier in multiple sclerosis. Arch Med Res 2014;45:687-97.

9. Motl RW, Pilutti LA. The benefits of exercise training in multiple sclerosis. Nat Rev Neurol 2012;8:487-97.

10. Langer-Gould A, Brara SM, Beaber BE, Koebnick C. Childhood obesity and risk of pediatric multiple sclerosis and clinically isolated syndrome. Neurology 2013;80:548-52.

11. Hedström AK, Olsson T, Alfredsson L. High body mass index before age 20 is associated with increased risk for multiple sclerosis in both men and women. Mult Scler 2012;18:1334-6.

12. Khurana SR, Bamer AM, Turner AP, Wadhwani RV, Bowen JD, Leipertz SL, et al. The prevalence of overweight and obesity in veterans with multiple sclerosis. Am J Phys Med Rehabil 2009;88:83-91.

13. Freeman J, Hobart J, Langdon D, Thompson A. Clinical appropriateness: a key factor in outcome measure selection: the 36 item short form health survey in multiple sclerosis. J Neurol Neurosurg Psychiatry 2000;68:150-6.

14. Negaresh R, Motl RW, Mokhtarzade M, Dalgas U, Patel D, Shamsi MM, et al. Effects of exercise training on cytokines and adipokines in multiple sclerosis: a systematic review. Mult Scler Relat Disord 2018; 24:91-100.

15. Koh SX, Lee JK. S100B as a marker for brain damage and blood-brain barrier disruption following exercise. Sports Med 2014;44:369-85.

16. Mirzaee Vishkaee K, Rahmaninia F, Elmieh A. The relationship between nutritional knowledge, body composition and physical activity level in middle-aged, obese and underweight females. J Sport Biomotor Sci 2013;5:33-43.

17. Storer TW, Davis JA, Caiozzo VJ. Accurate prediction of VO2max in cycle ergometry. Med Sci Sports Exe 1990;22:704-12.

18. Sebastião E, Sandroff BM, Learmonth YC, Motl RW. Validity of the timed up and go test as a measure of functional mobility in persons with multiple sclerosis. Arch Phys Med Rehabil 2016;97:1072-7.

19.Roh H-T, Cho S-Y, So W-Y. Obesity promotes oxidative stress and exacerbates blood-brain barrier disruption after high-intensity exercise. J Sport Health Sci 2017;6:225-230.

20. Langeskov-Christensen M, Heine M, Kwakkel G, Dalgas U. Aerobic capacity in persons with multiple sclerosis: a systematic review and meta-analysis. Sports Med 2015;45:905-23. 
21. Prakash RS, Snook EM, Motl RW, Kramer AF. Aerobic fitness is associated with gray matter volume and white matter integrity in multiple sclerosis. Brain Res 2010;1341:41-51.

22. Kodama S, Saito K, Tanaka S, Maki M, Yachi Y, Asumi M, et al. Cardiorespiratory fitness as a quantitative predictor of all-cause mortality and cardiovascular events in healthy men and women: a meta-analysis. JAMA 2009;301:2024-35.

23. Marrie RA, Cohen J, Stuve O, Trojano M, Sørensen PS, Reingold S, et al. A systematic review of the incidence and prevalence of comorbidity in multiple sclerosis: overview. Mult Scler 2015;21:263-81.

24. Langeskov-Christensen M, Bisson EJ, Finlayson ML, Dalgas U. Potential pathophysiological pathways that can explain the positive effects of exercise on fatigue in multiple sclerosis: A scoping review. J Neurol Sci 2017;373:307320.

25. Vgontzas AN, Bixler EO, Chrousos GP. Obesity- related sleepiness and fatigue. Ann N Y Acad Sci 2006;1083:32944.

26. Vgontzas AN, Papanicolaou DA, Bixler EO, Hopper K, Lotsikas A, Lin H-M, et al. Sleep apnea and daytime sleepiness and fatigue: relation to visceral obesity, insulin resistance, and hypercytokinemia. J Clin Endocrinol Metab 2000;85:1151-8.

27. Zimmer P, Bloch W, Schenk A, Oberste M, Riedel S, Kool J, et al. High-intensity interval exercise improves cognitive performance and reduces matrix metalloproteinases-2 serum levels in persons with multiple sclerosis: a randomized controlled trial. Mult Scler 2018;24:1635-44.

28. Burguera B, Couce ME, Curran GL, Jensen MD, Lloyd RV, Cleary MP, et al. Obesity is associated with a decreased leptin transport across the blood-brain barrier in rats. Diabetes 2000;49:1219-23.

29. Suwa M, Kishimoto H, Nofuji Y, Nakano H, Sasaki H, Radak Z, et al. Serum brain-derived neurotrophic factor level is increased and associated with obesity in newly diagnosed female patients with type 2 diabetes mellitus. Metabolism 2006;55:852-7.

30. Windsor MT, Bailey TG, Perissiou M, Meital L, Golledge J, Russell FD, et al. Cytokine Responses to Acute Exercise in Healthy Older Adults: The Effect of Cardiorespiratory Fitness. Front Physiol 2018;9:203.

31. Mokhtarzadeh M, Majdinasab N, Negaresh R, Ranjbar R. Association of relapse of multiple sclerosis with increased serum levels of leptin and decreased aerobic capacity in women. Isfahan Journal of Medical Science 2016;12:1-5.

32. Mokhtarzade M, Ranjbar R, Majdinasab N, Patel D, Shamsi MM. Effect of aerobic interval training on serum IL-10, $\mathrm{TNF} \alpha$, and adipokines levels in women with multiple sclerosis: possible relations with fatigue and quality of life. Endocrine 2017;57:262-71

33. Latimer-Cheung AE, Pilutti LA, Hicks AL, Ginis KAM, Fenuta AM, MacKibbon KA, et al. Effects of exercise training on fitness, mobility, fatigue, and health-related quality of life among adults with multiple sclerosis: a systematic review to inform guideline development. Arch Phys Med Rehabil 2013;94:1800-28.

34. Bitarafan S, Amani K, Sahraian MA, Sarraf P, Soltani D, Moghadasi AN, et al. The first attack of multiple sclerosis presented immediately after voluntary and intensive weight loss: a case series. Iran J Neurol 2017;16:41-2. 